\title{
Topics
}

\section{A Study on Paraffin-based Fuel Hybrid Rockets}

\author{
By Ichiro NAKAgAwA ${ }^{1)}$, Satoshi Hikone ${ }^{1)}$, Takafumi IsHIGURO $^{1)}$ and Shinya MARUYAmA ${ }^{1)}$ \\ ${ }^{1)}$ Department of Aeronautics and Astronautics, School of Engineering, Tokai University, Kanagawa, Japan
}

(Received June 18th, 2011)

\begin{abstract}
The most significant problem of a conventional hybrid rocket is its very low fuel regression rate; however, paraffin-based fuels are known to have a much higher regression rate. It was determined by Karabeyoglu et. al. that the materials with low surface tension and melt layer viscosity, such as paraffin-based fuels, generate more entrainment of liquid droplets, resulting in increased regression rates. It was very interesting model for us. Therefore we confirmed it experimentally by observing the burning fuels with a visualization chamber and revealed the high regression rate mechanism of paraffin-based fuels. And then we tried to increase the regression rate moreover with swirled oxidizer flow. It was quite effective, approximately twice of the regression rate of no swirl, but a large amount of liquid fuel was observed in the chamber. It is necessary to vaporize the liquid fuel rapidly to obtain high combustion efficiency. We tried to resolve this problem with a baffle plate set in the combustion chamber and obtained $3 \%$ combustion efficiency improvement.
\end{abstract}

Key Words: Hybrid Rocket, Paraffin, Regression Rate

$$
\begin{array}{ccl}
\text { Nomenclature } & \\
A & : & \text { area } \\
F & : & \text { evaluation function } \\
\dot{G} & : & \text { mass flux } \\
r & : & \text { regression rate } \\
\theta & : & \text { holes axis angle }
\end{array}
$$

Subscripts

$$
\begin{array}{lll}
c & : & \text { chamber cross section } \\
o & : & \text { oxidizer } \\
p & : & \text { holes cross section }
\end{array}
$$

\section{Introduction}

A hybrid rocket has many desirable features including safety, cost effectiveness, and reduced pollution. However, few hybrid rockets have been used on actual missions as a result of problems such as low regression rate and low volumetric efficiency. The low regression rate is a key problem on which there have been a lot of studies. Among these studies, Karabeyoglu et. al. ${ }^{1)}$ showed that the regression rate of paraffin-based fuel is almost four times that of a classical fuel such as HTPB. They determined that the materials with low surface tension and low viscosity melt layer, such as paraffin-based fuels, generate more entrainment of liquid droplets, resulting in increased regression rate. We consider paraffin-based fuel as one of the best candidates for the evolution of hybrid rockets. In this study, we observed to reveal the paraffin-based fuels high regression rate mechanism by visualizing the combustion process and tried to increase the regression rate moreover for actual use requirement. On the other hand, the combustion efficiency of a paraffin-based fuel hybrid rocket is rather low. It is caused by much melted fuel which isn't vaporized yet. So the combustion efficiency improvement is an important problem for this hybrid rocket.

\section{Paraffin-based Fuel Regression Mechanism}

\subsection{Paraffin-based fuel}

We used FT-105, FT-0070 and PW-120 made by Nippon Seiro Co., Ltd. as the fuel's paraffin base. They are not pure substances, but consist of many types of normal alkanes. Their physical properties are shown in table 1 . They are industrial materials produced in bulk; hence the price is very low, less than $\$ 10 / \mathrm{kg}$.

Table 1. Physical properties of paraffin.

\begin{tabular}{|c|c|c|c|}
\hline & FT-105 & FT-0070 & PW-120 \\
\hline $\begin{array}{c}\text { Melting Point } \\
{\left[{ }^{\circ} \mathrm{C}\right]}\end{array}$ & 102 & 72 & 50 \\
\hline $\begin{array}{c}\text { Flash Point } \\
{\left[{ }^{\circ} \mathrm{C}\right]}\end{array}$ & 294 & 258 & 214 \\
\hline $\begin{array}{c}\text { Density* } \\
{\left[\mathrm{g} / \mathrm{cm}^{3}\right]}\end{array}$ & 0.96 & 0.93 & 0.90 \\
\hline
\end{tabular}

* Density values are at room temperature.

Besides paraffin, we used ethylene-vinyl acetate copolymer (EVA), which has good mutual solubility with paraffin wax. We can increase the melted fuel's viscosity to increase content of EVA shown as Fig. 1. The viscosity data were measured with VT-03F rotating single cylinder viscosity meter made by Rion Co., Ltd. In this study, EV210ET made by Mitsui DuPont Chemical Co., Ltd. is used. It is also produced in bulk and is low priced too, around $\$ 4 / \mathrm{kg}$. Its chemical formula is $\mathrm{C}_{5} \mathrm{H}_{7} \mathrm{O}_{2}\left(\mathrm{CH}_{3}\right)$.

Five types of fuels are used in this series of experiments; the fuel compositions are shown in Table 2.

Table 2. Formulation of fuels (mass, \%)。

\begin{tabular}{|c|c|c|c|c|}
\hline No. & FT-105 & EV201ET & FT-0070 & PW-120 \\
\hline 1 & 100 & 0 & 0 & 0 \\
\hline 2 & 90 & 10 & 0 & 0 \\
\hline 3 & 80 & 20 & 0 & 0 \\
\hline 4 & 0 & 0 & 100 & 0 \\
\hline 5 & 0 & 0 & 0 & 100 \\
\hline
\end{tabular}




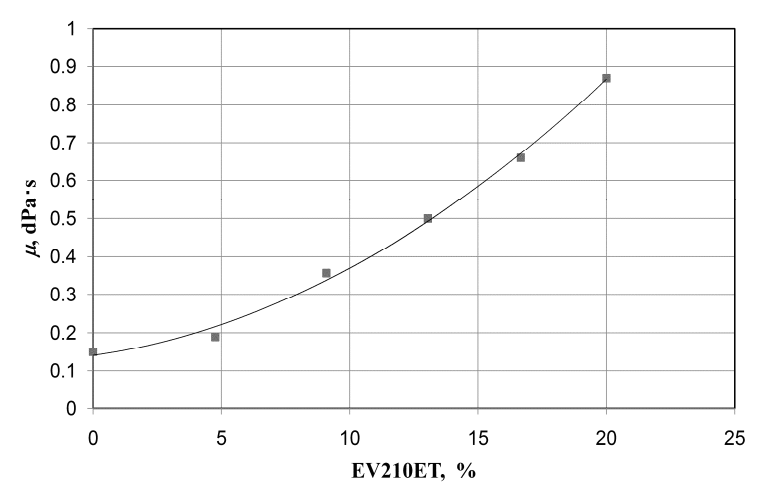

Fig. 1. Relation between melted fuel viscosity and EV210ET percentage at $120^{\circ} \mathrm{C}$.

\subsection{Experimental method}

We used the experimental apparatus shown in Fig. 2 to investigate paraffin-based fuel regression rate characteristics. The oxygen gas pressure is regulated to be less than $2 \mathrm{MPa}$; the regulator is installed at the tank exit. The orifice is installed downstream of the regulator to adjust the mass flow rate, and the pressure sensor is installed just upstream of the orifice shown as Fig. 3 to calculate the oxygen mass flow rate from the pressure data, the orifice cross-sectional area, and the flow coefficient, which are calibrated in advance. The inner cross-section shape between the orifice and the chamber is $10 \mathrm{~mm} \times 20 \mathrm{~mm}$, which is similar to the chamber's inner cross-section shape shown as Fig.4, in order to rectify the gas flow. The nitrogen supply line is installed downstream of the chamber to cool the exhaust gas and protect the exhaust pipe. The overview photograph of this apparatus is shown in Fig. 3.

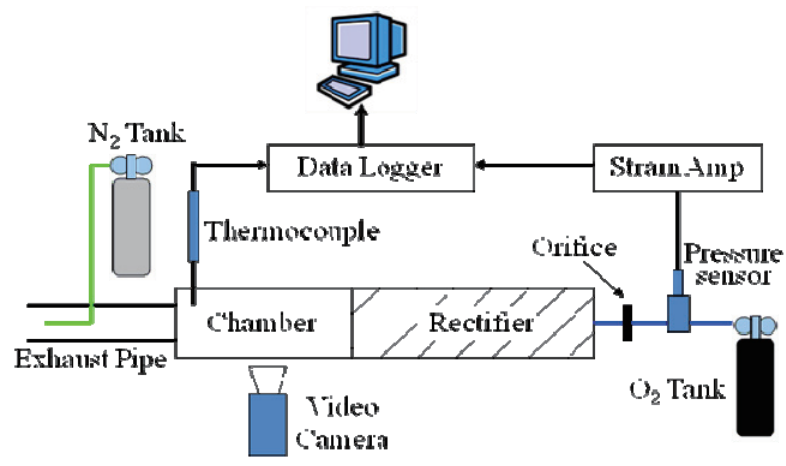

Fig. 2. Schematic of the experimental apparatus.

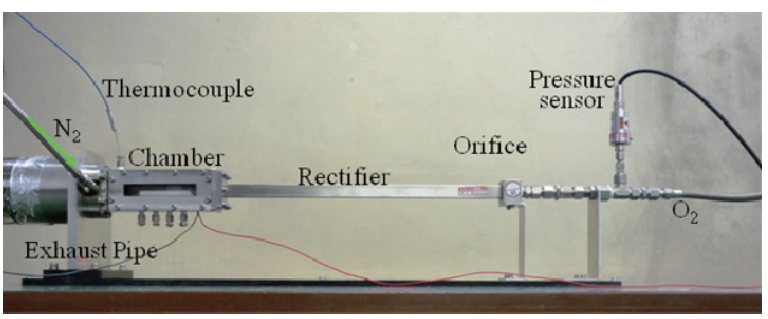

Fig. 3. Photograph of the experimental apparatus.

Windows made out of quartz glass can be attached to both sides of the chamber to observe the fuel combustion process. Paraffin-based fuel is sandwiched between windows as shown in Fig. 4. The fuel length, width, and height are $100 \mathrm{~mm}, 10$ $\mathrm{mm}$, and $10 \mathrm{~mm}$, respectively. It has a chamfer upstream as shown in Fig. 5. The fuel is ignited by a Nichrome wire installed at the forward fuel.

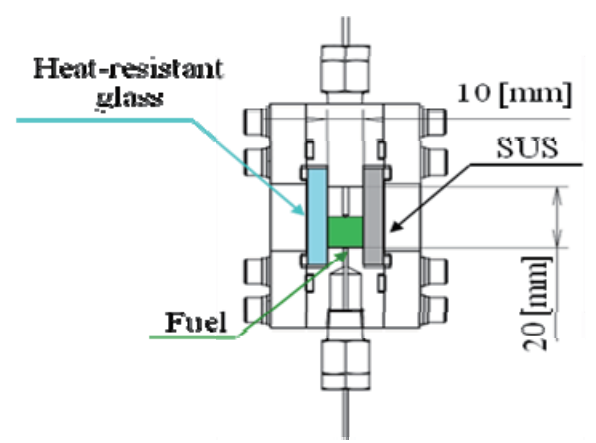

Fig. 4. Schematic of chamber cross-section.

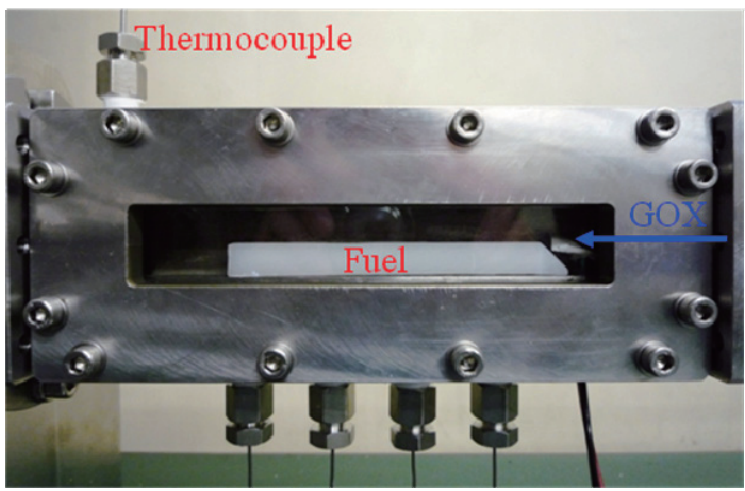

Fig. 5. Photograph of chamber set-up.

\subsection{Results and discussion}

The typical burning paraffin-based fuel photograph is shown in Fig. 6. A dark layer is observed between the solid phase fuel and the luminous flame zone. In this layer, there is a melted fuel flowing along the solid fuel surface. And many luminous entraining droplets are observed.

Therefore, it is confirmed experimentally that the melted-fuel flow layer is created on the solid phase fuel surface and entraining droplets exist actually, and in addition, some part of the melted fuel is flow away from the rear end of the solid fuel by a mechanical process.

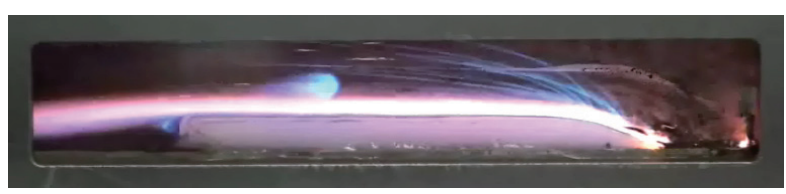

Fig. 6. Photograph of burning paraffin-based fuel.

From these observations, we consider the schematic model of the regression mechanism of a paraffin-based fuel shown as Fig. 7. There is a melted-fuel flow layer flowing on the solid fuel surface. Some part of the melted fuel is vaporized from the melted layer, but other parts of the melted fuel get entrained in the gas stream or flows along the solid phase fuel surface to the downstream end. The latter cases do not need more heat flux from the combustion gas stream to leave the solid phase as compared with vaporization. We consider that this is the high regression rate mechanism of paraffin-based fuels. 


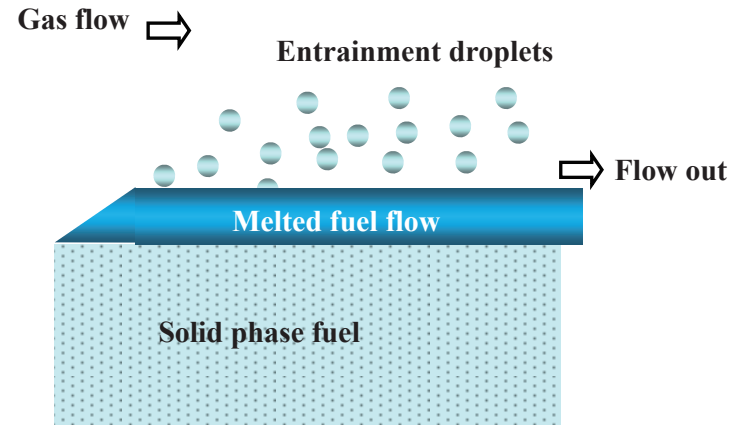

Fig. 7. Schematic model of the regression mechanism of a paraffin-based fuel.

We analyzed the regression rate with video data. The relation between regression rate of FT-105 based fuel and oxidizer mass flux is shown as Fig. 8. The regression rate of EV210ET 0\% fuel (No. 1) is the highest; that of EV210ET 10\% (No. 2) is the second highest; and that of EV210ET 20\% (No. 3) is the lowest. These values mean that the regression rate decreases as the percentage of EV210ET increases. Therefore, it increases as the melted fuel viscosity decreases.

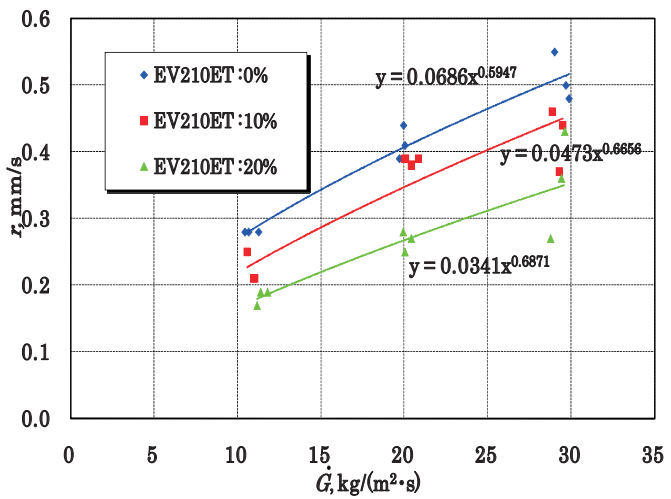

Fig. 8. The relation between regression rate and oxidizer mass flux (FT-105 based fuel).

The relation between regression rate of some paraffin fuels and oxidizer mass flux is shown as Fig. 9. The regression rate of PW-120 is highest. Next is FT-0070. Third is FT-105.

According to the Table 1, the melting point is lower, the regression rate is higher. Those regression rates are lower than ref. 1 data. The reason is considered to be more heat loss of $2 \mathrm{D}$ visualized chamber than that of a cylindrical motor.

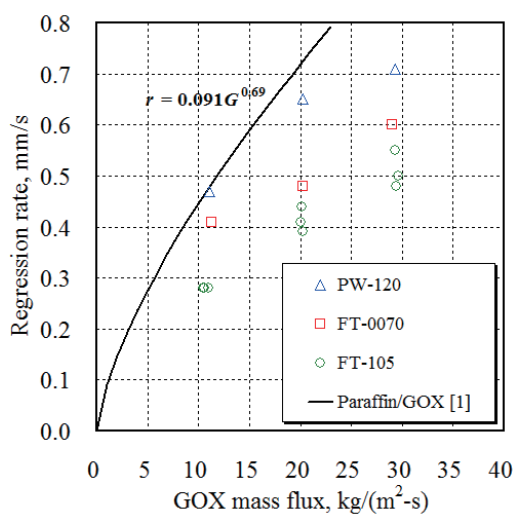

Fig. 9. The relation between regression rate and oxidizer mass flux (Some kinds of paraffin fuels).

\section{To Increase the Regression Rate Moreover}

The regression rate of a paraffin-based fuel is much higher than that of a conventional fuel as we mentioned. But it is necessary to increase the regression rate much more for some cases among satellite launching rockets. Therefore, we tried to increase the regression rate of a paraffin-based fuel with oxidizer swirl flow, since it is known that oxidizer swirl flow increase regression rate effectively.

\subsection{Experimental method}

The schematic drawing of the chamber is shown as Fig. 10. Gas oxygen is supplied to fuel cartridge through an injector. The injector has four holes of which center axis is at $\theta$ angle shown as Fig. 11. So oxidizer flow is swirled. Fuel cartridge is acrylic acid resin pipe which contains paraffin fuel. The paraffin fuel is FT-0070, since melting point of $\mathrm{PW}-120,50^{\circ} \mathrm{C}$ is too low for practical use. The chamber exit is an unchoked nozzle, so the chamber pressure is almost atmospheric pressure.

The experiments were conducted with two type injectors. Their $\theta$ values are $30^{\circ}$ and $45^{\circ}$.

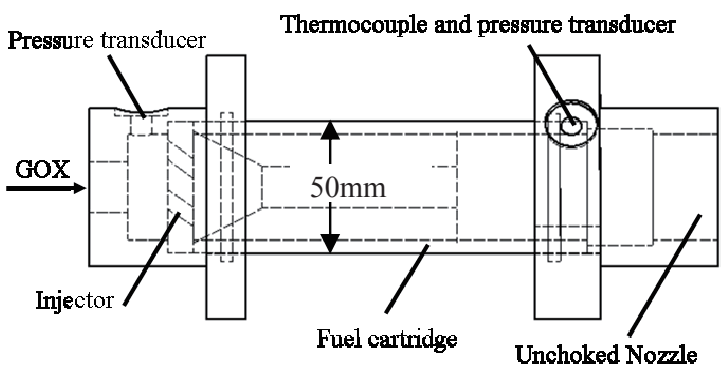

Fig. 10. Schematic drawing of the chamber.

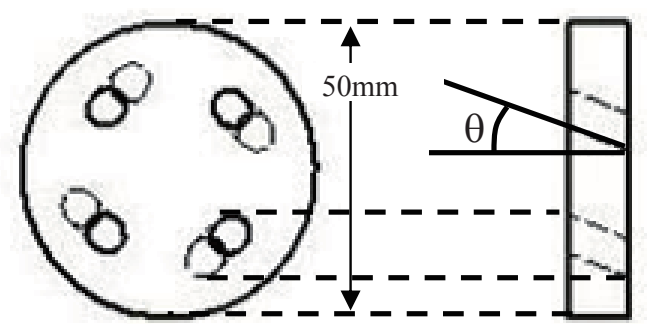

Fig. 11. Schematic drawing of the injector.

\subsection{Results and discussion}

The regression rate data are shown in Fig. 12. The regression rate of $45^{\circ}$ injector is highest. It is approximately twice of that of no swirl at oxygen mass flux $10 \mathrm{~kg} /\left(\mathrm{m}^{2} \mathrm{~s}\right)$.

Therefore, we consider that higher intensity swirl flow makes regression rate higher.

\section{Improvement of the Combustion Efficiency}

We can increase regression rate with oxidizer swirl flow. But it produces much liquid fuel i.e. not vaporized fuel in the chamber shown as Fig. 13. Therefore, the combustion efficiency of this rocket is considered to be very low. Then we tried to improve combustion efficiency. 


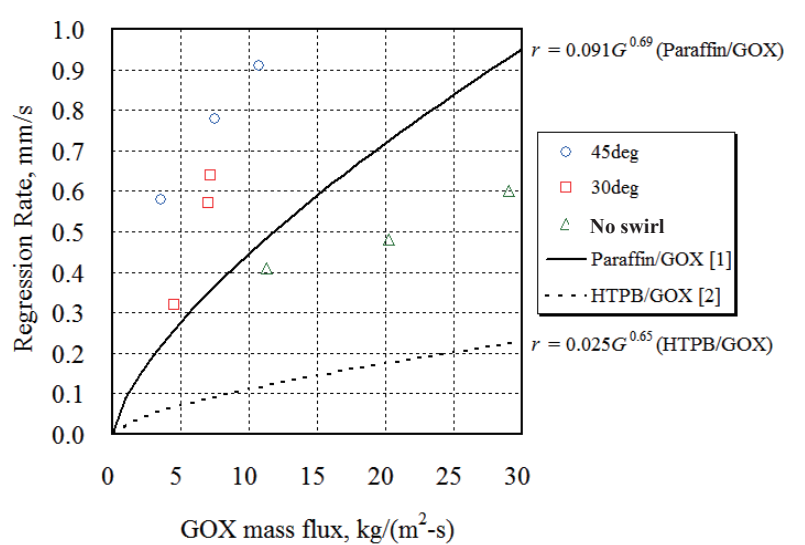

Fig. 12. Regression rate data on oxidizer swirl flow effect.

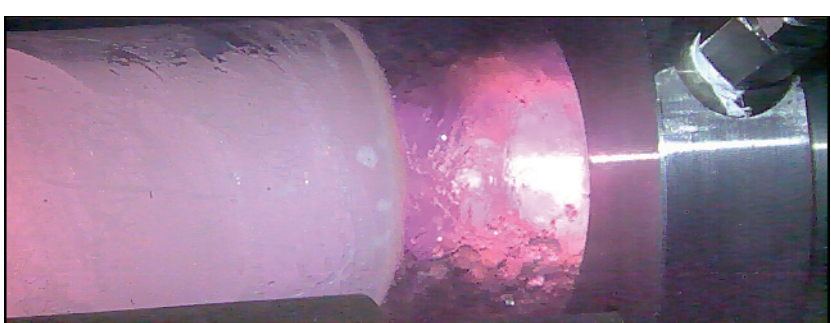

Fig. 13. Photograph of the chamber during a burning experiment with oxidizer swirl flow.

\subsection{Experimental method}

We adopted a baffle plate to improve combustion efficiency. It is expected to enhance atomization of melted paraffin fuel.

The schematic drawing of the the chamber containing baffle is shown in Fig 14. We used four types of baffle plate shown as Fig. 15. They have 4 to 7 holes which is $10 \mathrm{~mm}$ in diameter.

The chamber exit is choked nozzle. We measure chamber pressure and calculate $\mathrm{c}^{*}$ to analyze combustion efficiency.

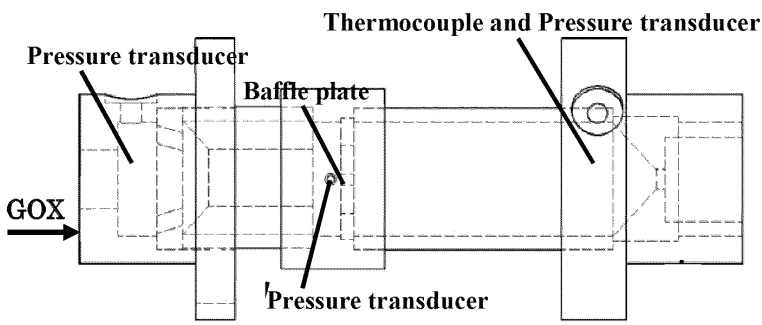

Fig. 14. Schematic drawing of the chamber containing baffle plate

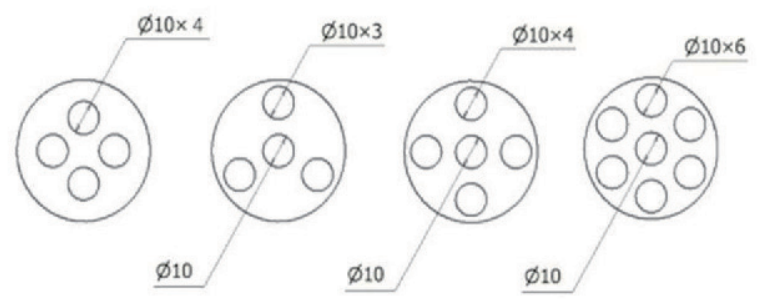

Fig. 15. Schematic drawing of the baffle plates.

\subsection{Results and discussion}

c*efficiency data is shown in Fig. 16. The Evaluation function is defined as follows.

$$
F=A_{p} / A_{c}
$$

$c^{*}$ efficiency increases from 79 to $82 \%$ as $F$ decreases. The pressure loss through the baffle plate was negligible small even $F$ is smallest. Therefore, $F$ can be made smaller to increase $c^{*}$ efficiency.

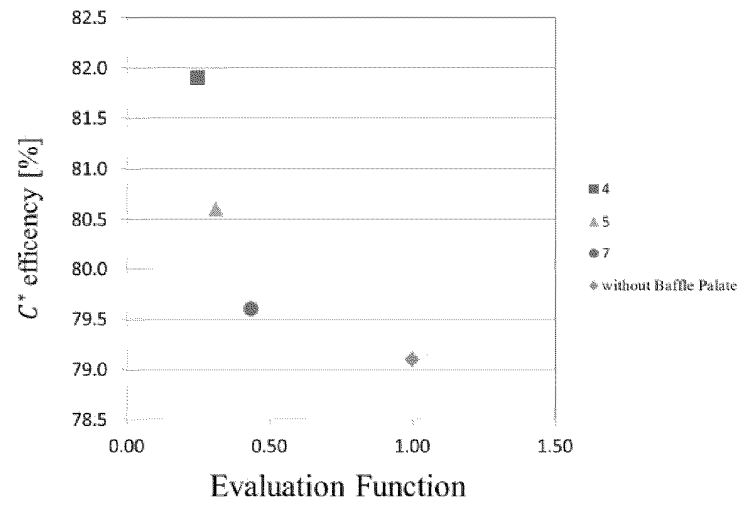

Fig. 16. c* efficiency data

\section{Conclusions}

1) High regression rate mechanism of paraffin-based fuel is revealed with a visualized chamber.

2) The regression rate can be increased with oxidizer swirl flow.

3) Combustion efficiency of paraffin-based fuel rocket is improved with a baffle plate.

\section{Acknowledgments}

This research is conducted as a contribution to the Hybrid Rocket Research Working Group (HRrWG) with the approval of the Space Engineering Committee of Institute of Space and Astronautical Science, Japan Aerospace Exploration Agency. The authors thank members of HRrWG for their helpful discussion.

\section{References}

1) Karabeyoglu, M. A., Cantwell, B. J. and Altman, D.: Development and Testing of Paraffin-based Hybrid Rocket Fuels, AIAA paper, No.2001-4503, 37th AIAA/ASME/SAE/ASEE Joint Propulsion Conference and Exhibit,(2001).

2) Karabeyoglu, M. A., Zilliac, G., Cantwell, B. J., Zilwa, S. D. and Castelluci, P.: Scale-up Tests of high Regression Rate Liquefying Hybrid Rocket Fuels, AIAA paper, No.2003-6475, 39th AIAA/ASME/SAE/ASEE Joint Propulsion Conference and Exhibit, (2003).

3) Karabeyoglu, M. A.: Thermal Transients in Hybrid Rocket Fuel Grains - Nonlinear Effects, AIAA paper, No.2007-5369, 43rd AIAA/ASME/SAE/ASEE Joint Propulsion Conference and Exhibit, (2007) 